\title{
SHORT PULSE ELECTRON LINAC WITH FULL BEAM LOADING COMPENSATION
}

\author{
V.V. Mytrochenko ${ }^{1}$, S.O. Perezhogin ${ }^{1}$, V.Ph. Zhyglo ${ }^{1}$, A.M. Opanasenko ${ }^{1,2}$ \\ ${ }^{1}$ National Science Center "Kharkov Institute of Physics and Technology”, Kharkiv, Ukraine; \\ ${ }^{2}$ V.N. Karazin Kharkiv National University, Kharkiv, Ukraine \\ E-mail: mitvic@kipt.kharkov.ua; opanasenko@kipt.kharkov.ua
}

Acceleration of intense short-pulsed electron beams in transient mode with energy spread about a few tenths of a percent is the actual problem for RF linacs, in an instance, for an electron injector of a storage ring. In this work we study both analytically and numerically unsteady self-consistent beam dynamics in the one section RF linac fed from SLED. For compensation of the transient beam loading, resulting in beam energy spread, a method of a beam delay with respect to RF pulse is consider. In order to increase efficiency of this method we choose a homogenous dick-loaded waveguide with $\pi / 2$ phase advance as an accelerating structure that characterized by the minimal frequency dispersion of group velocity. The preliminary results show that the full beam loading compensation is possible for the $1.2 \mathrm{~A}$ beam at its acceleration up to $60 \mathrm{MeV}$ during $50 \mathrm{~ns}$.

PACS: 29.20.Ej, 84.40.-x

\section{INTRODUCTION}

Acceleration of intense short-pulsed electron beams in transient mode with energy spread about a few tenths of a percent is the actual problem for RF linacs, for the instance, the injector for the storage ring [1]. Thus the development of both bunching system, providing a small energy and phase spread, and beam loading compensation techniques are required. Reaching of a small energy spread is restricted by as transient beam loading so a lot of others factors, namely: energy and phase spread of bunches injected in an accelerating section and their temporal dependences of average phase and energy; sliding of particles with respect to wave phase; space charge effects.

There are several basic techniques of the beam loading compensation, namely $\Delta \mathrm{T}, \Delta \mathrm{S}, \Delta \mathrm{F}$ schemes. The $\Delta \mathrm{T}$ scheme consists in a beam injection before an RF pulse has filled a section $[2,3]$. The method $[4,5]$ where an RF waveform is linearly ramped during the filling time of a structure is classified in [6] as the $\Delta \mathrm{S}$ scheme. Additional $\mathrm{RF}$ structures operating at slightly different frequencies ( $\Delta \mathrm{F}$ scheme) have been proposed by authors [7] to compensate the beam voltage. They have shown that the combination of the $\Delta \mathrm{T}+\Delta \mathrm{S}+\Delta \mathrm{F}$ techniques can save over $30 \%$ of RF power. It should be noted that the techniques mentioned above, as a rule, were developed for the SLED [8] driven constant-gradient accelerators structures.

The purpose of this paper to study both analytically and numerically enable of beam loading compensation by the $\Delta \mathrm{T}$ scheme in in one section S-band RF linac operating in short-pulsed mode fed from SLED.

\section{BEAM LOADING COMPENSATION}

\subsection{LOADED ACCELERATING FIELD}

The $\Delta \mathrm{T}$ scheme of beam loading compensation is the simplest technique which has the advantage when bunch train length shorter the filling time notably [2]. Let us consider the characteristics of the $\Delta \mathrm{T}$ scheme used for a single constant-impedance $(\mathrm{CZ})$ accelerating structure taking account finite width of rise/fall time of an input RF waveform.

Starting from the equations of excitation of waveguides by both an external RF pulse and a beam pulse, using Laplace transformation the time dependent of a longitudinal electric field over a $\mathrm{CZ}$ section can be derived in general form [9]

$$
\begin{aligned}
& E(t, z)=\operatorname{Re}\left\{e^{-i \omega\left(t_{0}+\frac{z}{c}\right)} \int_{0}^{t} E_{0}\left(t-t^{\prime}\right) G\left(t^{\prime}, z\right) d t^{\prime}\right. \\
& \left.-\frac{\omega R_{\text {sh }}}{2 Q}\left[q_{\text {eff }}(t)-e^{-i \frac{\omega}{c} z} \int_{0}^{t} q_{\text {eff }}\left(t-t^{\prime}\right) G\left(t^{\prime}, z\right) d t^{\prime}\right]\right\},
\end{aligned}
$$

where $t$ is time, $\mathrm{z}$ is a longitudinal coordinate; $E_{0}(t)$ is the envelope of an input RF pulse, $\omega$ is the angular operating frequency, $Q$ is the quality of cells, $c$ is the speed of light, $G(t, z)$ is the delta-function response of the waveguide [2], $R_{s h}$ is the shunt impedance, $q_{\text {eff }}$ is the effective macro charge of the beam, determined as $q_{\text {eff }}(t)=e^{-\frac{\omega}{2 Q} t^{t}} \int_{0}^{t} I\left(t^{\prime}\right) e^{\frac{\omega}{2 Q} t^{\prime}} d t^{\prime}, I(t)$ is the beam current averaged over an RF period. The beam pulse is the train of ultra-relativistic point electron bunches. The charge of a bunch is $q(t)=I(t) 2 \pi / \omega$.

Let us consider a case of neglecting dispersive effects

$$
G(t, z)=\delta\left(t-z / \mathrm{v}_{g}\right) e^{-\frac{\omega}{2 Q_{g}} z+i \frac{\omega}{c}} \equiv G_{o f f}(t, z)
$$

where $\mathrm{v}_{g}$ is the group velocity. Let an accelerating section of length $L$ is fed at its upstream end by an input RF waveform with linear rise time $\Delta t_{\text {rise }}$ that travels to the other end without reflection (Fig. 1).

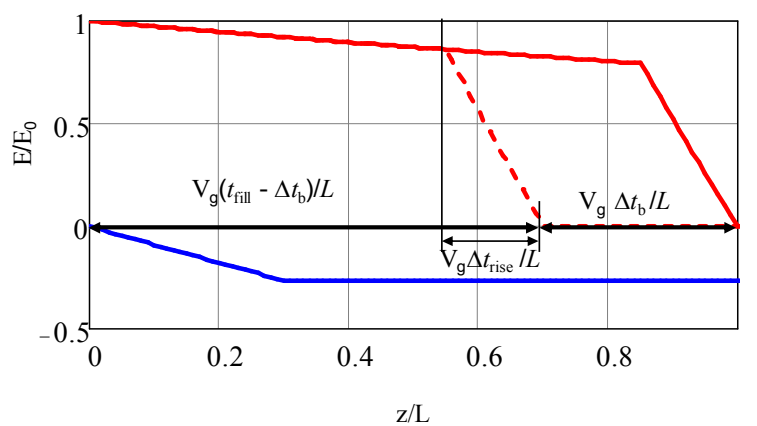

Fig. 1. A snapshot RF waveforms of fields from both an $R F$ source (red lines) and a beam (blue line) at the time of the beam switching on/off (dashed/solid lines) 
A beam pulse with duration $\Delta t_{b}$ and zero time of rise and fall is started to inject before the full fill of the section at the time $t_{0}=t_{f i l}-\Delta t_{b}$ (where $t_{\text {fill }}$ is the filling time). Also the blue line in Fig. 1 illustrates the field induced by the beam in the time $t_{0} \leq t \leq t_{\text {fill }}$. After integrating Eq. (1) over the length $L$, we can find the condition of beam loading compensation under which the linear time dependence of the energy gain disappears

$$
\frac{\Delta t_{b}}{2 t_{\text {fill }}}=1-\frac{1}{I} \sqrt{\frac{2 P L}{\tau R_{\text {sh }}}} \exp \left[-\tau\left(1-\frac{\Delta t_{b}}{t_{\text {fill }}}-\frac{\Delta t_{\text {rise }}}{2 t_{\text {fill }}}\right)\right],
$$

where $\tau=\omega t_{\text {fill }} / 2 Q$ is the attenuation factor, $P$ is the input RF power. In this case the energy gain has a nearparabolic time profile, and the small energy spread along the bunch train is achieved. The leading and trailing bunches have the same energy and the central bunches have a lower energy (Fig. 2).

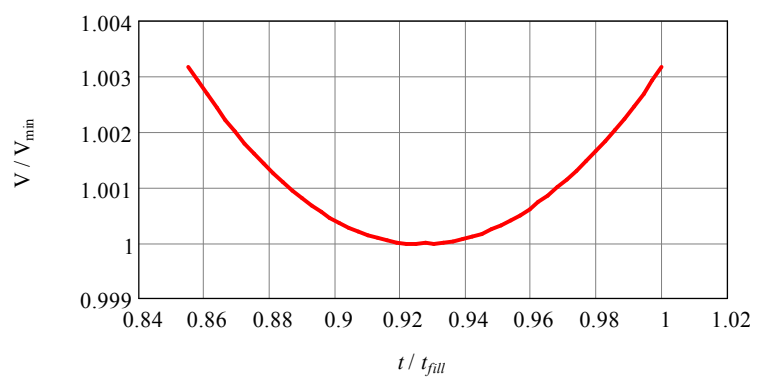

Fig. 2. A normalized beam loaded accelerating voltage as a function of time under the beam compensation

In this situation, rms energy spread along a bunch train can be derived in the form

$$
\sigma=\frac{1}{12 \sqrt{5}} \frac{(\tau v)^{2} e^{-\frac{\tau v}{2}}}{\tau\left(1-\frac{v}{2}\right)\left(e^{\tau\left(1-v-\frac{\varepsilon}{2}\right)}-1\right)+1-\frac{\tau v}{2}-e^{-\frac{\tau v}{2}}+\frac{(\tau v)^{2}}{24} e^{-\frac{\tau v}{2}}},
$$

where $v=\Delta t_{b} / t_{\text {fill }}, \varepsilon=\Delta t_{\text {rise }} / t_{\text {fill }}$.

The $v$ - dependences of the rms energy spread at $\tau=0.5$ are plotted in Fig. 3 .

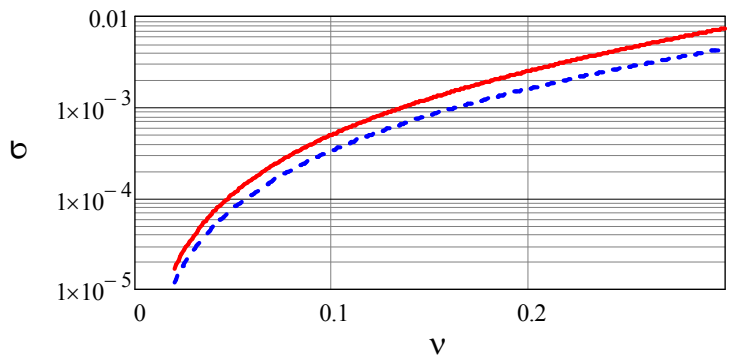

Fig. 3. A rms energy spread as a function of $v$ at $\varepsilon=0.5$ (solid red line), and $\varepsilon=0$ (dashed blue line), respectively

The rms energy spread weakly dependents on both the attenuation factor and the width of the wave-front. Therefore, the beam loading compensation technique taking account a finite rise time of an RF waveform can provide the rms energy spread of about $0.1 \%$ at the beam duration less than $0.15 t_{\text {fill }}$, although the finite rise time reduces the accelerating gain.

\subsection{IMPACT OF DISPERSIVE EFFECTS}

A RF waveform is distorted upon propagating along an accelerating structure due to a dispersive law

$$
\omega=\omega_{m}-\omega_{c} \cos \theta,
$$

where $\omega_{c}=\omega_{0} \beta_{g}\left(\omega_{0}\right) /\left(\theta_{0} \sin \theta_{0}\right)$ is the half width of the pass band, $\omega_{\mathrm{m}}$ is the midband angular frequency, $\omega_{0}$ is the operational frequency, $\theta_{0}$ is the phase advance per a cell at the operational frequency, $\beta_{g}=\mathrm{v}_{g} / c$ is the relative group velocity.

To take into account (5), we can use in Eq. (1) the good approximation of the delta-function response for the disk loaded waveguides (DLW) [2]

$G(t, z)=\frac{z}{D} J_{\frac{z}{D}}\left(\omega_{c} t\right) \exp \left[i\left(\frac{z}{D}\left(\frac{\pi}{2}-\theta\right)-\left(w_{m}-\omega\right) t\right)-\frac{w_{n} t}{2 Q}\right] \equiv G_{o n}(t, z),(6)$ where $D$ is the DLW period.

Consider the RF pulses with initially linear rise times $\Delta t_{\text {rise }}(10$ and $50 \mathrm{~ns})$, which propagate through accelerating structures with differing phase advances per a cell $(2 \pi / 3$ and $\pi / 2)$ at the operating frequency $2797 \mathrm{MHz}$, but having the same both group velocity $\beta_{g}=0.04$ of the light velocity and the filling time $t_{\text {fill }}=292$ ns. In Fig. 4 it is given the snapshots of the RF waveforms distributed along the $2 \pi / 3$ structures both with the dispersive effect (solid line) and without it (dot line) at the time $t \in\left[0, t_{\text {fil }}\right]$.

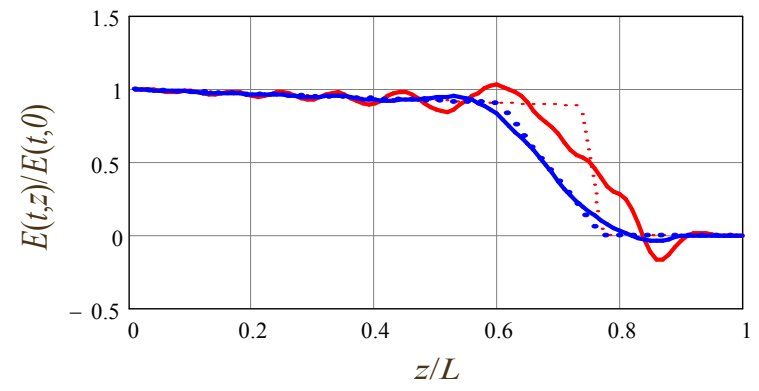

Fig. 4. Snapshots of normalized RF waveforms in the $2 \pi / 3$ structure. The red and blue lines correspond

to $\Delta t_{\text {rise }}=10$ and $50 \mathrm{~ns}$ respectively. The solid and dot lines correspond to the dispersive law (5) and without it, respectively

In order to estimate impact of the dispersive effects one can introduce a quantitative indicator as

$$
\delta V(t)=2 \frac{V_{o n}(t)-V_{o f f}(t)}{V_{o n}(t)+V_{o f f}(t)},
$$

where $V_{\text {on/off }}=\int_{0}^{L} d z \int_{0}^{t} E_{0}\left(t-t^{\prime}\right) e^{-\frac{\omega}{2 Q} t^{\prime}} G_{\text {on/off }}\left(t^{\prime}, z\right) d t^{\prime}$ is the unloaded accelerating voltage both with the dispersive effect and without it. The Fig. 5 illustrates the temporal dependences of the ratio (7).

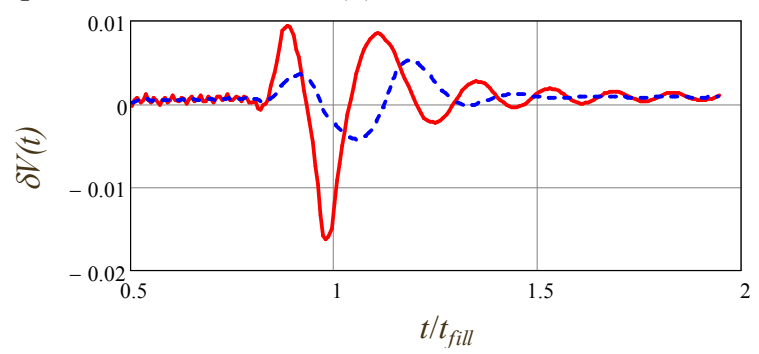

Fig. 5. $\delta V(t)$ as function of time for two RF pulses with rise times $10 \mathrm{~ns}$ (red solid line) and $50 \mathrm{~ns}$ (blue dashed line) propagating in the $2 \pi / 3$ structure 
One can see, that for the injection time in the region $0.8 t_{\text {fill }}<t<1.2 t_{\text {fill }}$ the contribution of the dispersive effects to the beam energy spread is 0.01 by order of magnitude. The energy spread can be decreased by lengthening the rise time.

To exclude contribution of the phase modulation to the energy spread the structure with $\pi / 2$ phase advance per a cell may be chosen, as it follows from (6). The corresponding snapshot RF waveforms are plotted in Fig. 6. The next Fig. 7 demonstrates the significant reduction of the influence of dispersive effects on the beam energy spread in the $\pi / 2$ structure compare with the $2 \pi / 3$ structure (see Fig. 5).

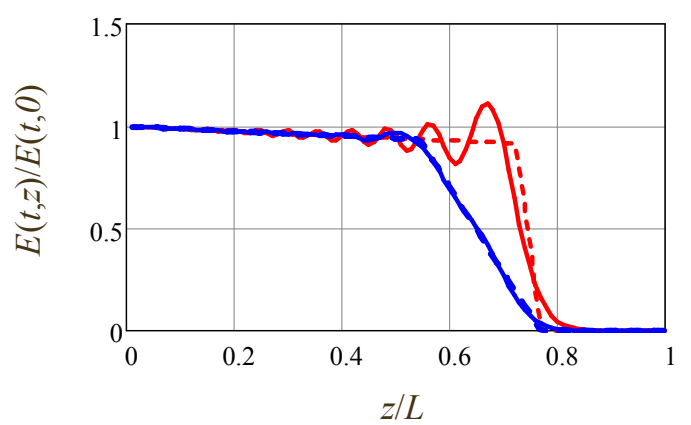

Fig. 6. Snapshots of RF waveforms in the $\pi / 2$ structure. The red and blue lines correspond to $\Delta t_{\text {rise }}=10 \mathrm{~ns}$ and 50 ns respectively. The solid and dot lines correspond to the dispersive law (5) and without it, respectively

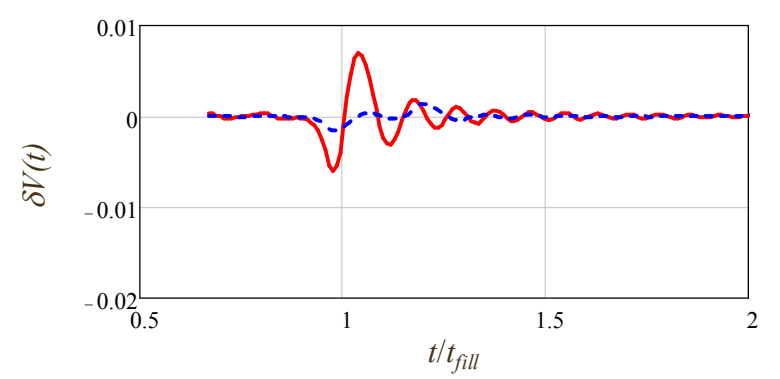

Fig. 7. $\delta V(t)$ as function of time for two RF pulses with rise times $10 \mathrm{~ns}$ (red solid line) and $50 \mathrm{~ns}$ (blue

dashed line) propagating in the $\pi / 2$ structure

Therefore, comparing the Figs. 7 and 5 one can see that the $\pi / 2$ structure is more insensitive to the dispersive effects compared with the $2 \pi / 3$ structure.

\section{THE SHORT PULSE RF LINAC} 2.1. LAYOUT OF THE RF LINAC

Demonstration of the technique mentioned above has been performed on the S-band RF linac outlined in Fig. 8. The linac can be considered as a prototype for upgrade of the injector [10] for the storage ring NESTOR. According to [1] the ring can accumulate electrons injected from a linac in up to 36 buckets circulating on a reference orbit (bucket repetition rate is $700 \mathrm{MHz}$, repetition time of buckets is $50 \mathrm{~ns}$ in this case). The ultimate goal for the main parameters of injected beam are as follows: electron beam energy $60 \mathrm{MeV}$, transversal emittance $5 \times 10^{-7} \mathrm{~m} \cdot \mathrm{rad}$; energy spread $1 \%$; bunch charge $0.5 \mathrm{nC}$; bunch duration $10 \mathrm{ps}$; bunch repetition rate $700 \mathrm{MHz}$.
It is shown below that the proposed linac layout can advance substantially injected beam parameters to the final goal.

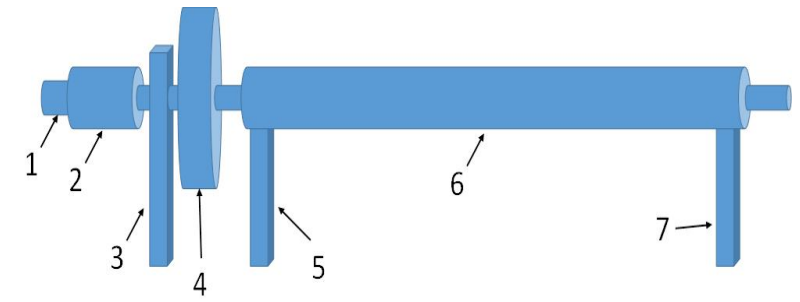

Fig. 8. Layout of the one section RF linac:

1 -the electron gun; 2 -the evanescent wave buncher; 3 - the waveguide to the coaxial lancher;

4 -the short solenoid; 5 and 7 are the waveguides to the DLW coupler; $6-D L W$

The RF linac consists of the evanescent wave injector [11] and one accelerating section of the "Kharkov65 " type [12]. The injector contains the $25 \mathrm{kV}$ diode gun and the five-cell evanescent wave buncher that is fed with RF power through the waveguide to the coaxial lancher. The electron source of the gun is an impregnated cathode that has $1.5 \mathrm{~mm}^{2}$ area. Depending of the gun modification it can generate the 1 to $2 \mathrm{~A}$ of electron current. The gun can be equipped with the EIMAC Y$646 \mathrm{E}$ cathode-grid assembly. In this way it will become the triode gun with current up to $3 \mathrm{~A}$. The anode opening of the gun coincide on axis with the opening of the first cavity of the buncher that accelerate a beam to the $1 \mathrm{MeV}$ range of energy. Downstream of the injector the beam injected into accelerating section focusing with short solenoid. The section is a constant impendence DLW with the phase advance $\pi / 2$ per a cell containing 162 cells that corresponds the section length, $\mathrm{L}=4.342 \mathrm{~m}$. Phase velocity of the wave is equal to the velocity of light $\mathrm{c}$ at the frequency, $2 \pi \omega=2797.15 \mathrm{MHz}$. The relative group velocity is $\beta_{\mathrm{g}}=0.04$, the attenuation is $\alpha=\omega /\left(2 Q \mathrm{v}_{g}\right)=0.0611 / \mathrm{m}$. The shunt impedance is $R_{s h}=47.6 \mathrm{M} \Omega / \mathrm{m}$.

Needed level of RF power for the acceleration section can be provided with a SLED technology operating in regime of flat top pulse generation, for example with a SLED-II scheme $[13,14,18]$ or either phase or a frequency modulation scheme $[15,16]$. The SLED-II scheme allows to get the power gain of about four but needs two lengths of resonant line. The $[16,17]$ scheme is based on the original SLED scheme with two high Q resonators but allows to get the power gain just about two.

Depending of the chosen SLED scheme for the linac we have cases with high and low accelerating gradients taking into account maximal output power of the linac klystron. On the other hand, the electron gun can have diode or triode configuration. Therefore, three variants have been considered overall: a high gradient case with a diode gun; a high gradient case with a triode gun; low gradient case with triode gun.

It is supposed that RF power for the buncher is splitted from the RF power feeding the acceleration section so the both RF pulses have the same time profile. 


\subsection{ANALYTICAL ESTIMATION}

Integrating Eq. (1) over the length $L$ with neglecting dispersive effects (2) and using the ratio (3) we can to estimate the combination of optimum values of such parameters as average energy gain, a beam current, an RF power by choosing a beam time delay with respect to an RF waveform. We consider both high and low gradient acceleration.

In the first case we suppose that the accelerating structure is supplied by a flat pulse of RF power of $58.3 \mathrm{MW}$ with the linear rise time of $36 \mathrm{~ns}$. The beam pulse has the flat top of lasting of $\Delta t_{b}=50 \mathrm{~ns}$ and the linear rise and fall time of $\Delta t_{\text {rise/fall }}=5 \mathrm{~ns}$. The value of beam current is chosen to get both the average energy gain close to $60 \mathrm{MeV}$ and minimum rms energy spread. The energy gain as function of time has the form shown in Fig. 9. This temporal energy gain distribution obtained for the beam current of 1.284 A provides at the beam time delay $\left(\Delta t_{\text {delay }}=t_{\text {fill }}-\Delta t_{b}-2 \Delta t_{\text {rise }}\right)$ the average energy gain of $56.3 \mathrm{MeV}$ and the multi-bunch rms energy spread of about $0.128 \%$. The energy gain plotted in Fig. 9, unlike the similar dependence with the zero rise and fall time of the beam current pulse shown in Fig. 2, has the "mustache" of low energy (leading bunches) and high energy (trailing ones), due to the finite time of rise and fall of the simulated current pulse.

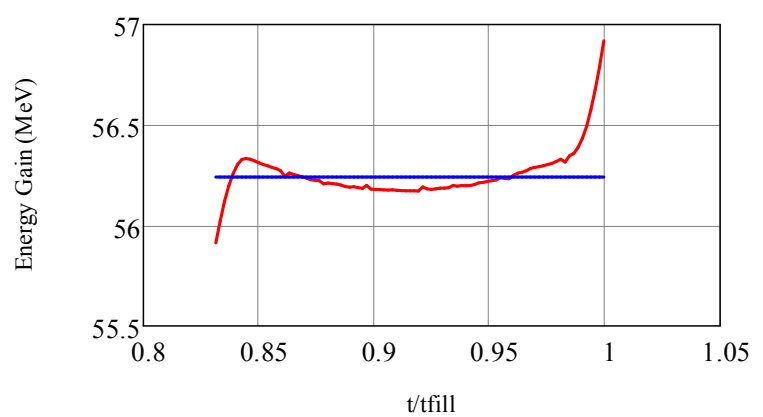

Fig. 9. A loaded accelerating energy gain as a function of time (the red curve). The blue line corresponds the average energy gain. $P=58.3 \mathrm{MW}, I=1.284 \mathrm{~A}$, rms energy spread of about $0.128 \%$

In order to increase the average energy gain without growing the beam energy spread and without increasing the RF power it turned out the beam can be injected later $\Delta t_{\text {delay }}=t_{\text {fill }}-0.6 \Delta t_{b}-2 \Delta t_{\text {rise }}$. It results in growing the average energy up to $59.9 \mathrm{MeV}$ (Fig. 10).

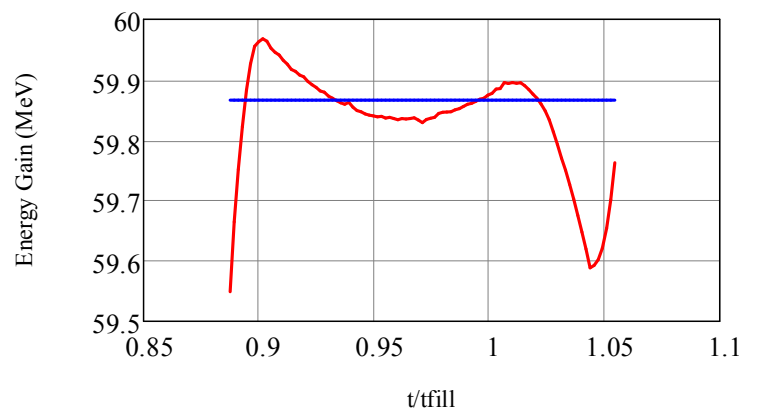

Fig. 10. A loaded accelerating energy gain as a function of time (the red curve). The blue line corresponds the average energy gain. $P=58.3 \mathrm{MW}, I=1.258 \mathrm{~A}$, rms energy spread of about $0.08 \%$
In the case of low gradient acceleration, we consider ability to decrease the fed RF power down to $36 \mathrm{MW}$. It leads to essential decreasing the pulse current up to $I=0.6 \mathrm{~A}$ and lengthening the accelerating section up to $L=6.03 \mathrm{~m}$. The energy gain as function of time is shown in Fig. 11. This temporal energy gain distribution obtained for the beam current of $0.6 \mathrm{~A}$ provides at the beam time delay $\left(\Delta t_{\text {delay }}=t_{\text {fill }}-\Delta t_{b}-2 \Delta t_{\text {rise }}\right)$ the average energy gain of $60.6 \mathrm{MeV}$ and the multi-bunch rms energy spread of about $0.062 \%$.

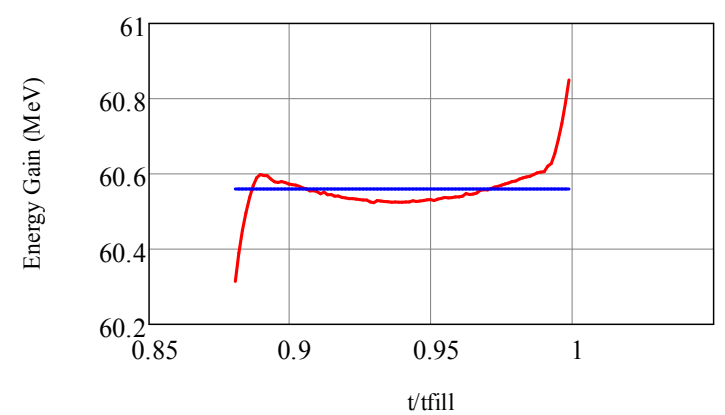

Fig. 11. A loaded accelerating energy gain as a function of time (the red curve). The blue line corresponds the average energy gain. $P=32 \mathrm{MW}, I=0.6 \mathrm{~A}, \mathrm{rms}$ energy spread of about $0.062 \%$

To increase the average energy gain up to $63 \mathrm{MeV}$ keeping the beam energy spread the beam can be injected later $\Delta t_{\text {delay }}=t_{\text {fill }}-0.6 \Delta t_{b}-2 \Delta t_{\text {rise }}$. The result can be seen in Fig. 12.

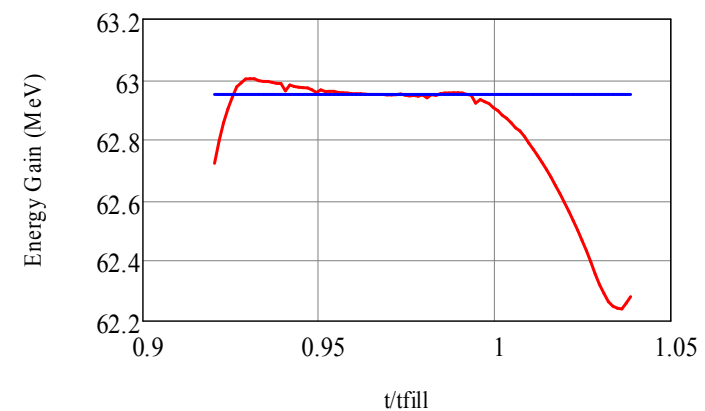

Fig. 12. A loaded accelerating energy gain as a function of time (the red curve). The blue line corresponds the average energy gain. $P=32 \mathrm{MW}, I=0.6 \mathrm{~A}, \mathrm{rms}$ energy spread of about $0.062 \%$

Impact of finite phase width of the bunches and phase slippage of ones in an accelerating wave can be taken into account with numerical simulation.

\subsection{NUMERICAL SIMULATIONS}

In order to simulate numerically transient beam dynamics in the buncher and the traveling wave section we use the unsteady self-consistent technique [17] that incorporates PARMELA code [18]. This technique is based on unsteady theory of excitation of resonators and spatially inhomogeneous traveling wave accelerating structures. A motion of charged particles at each integration time step simulated by the PARMELA code allows taking into account bunch space charge fields. To find the parameters of axially symmetric electrodynamic and magnetic systems needed for simulation, the SUPERFISH/POISSON group of codes [19] were used, as well as the technique [20]. The thermionic electron gun is designed with the well-known EGUN codes [21]. 


\subsection{HIGH GRADIENT ACCELERATION}

In order to get the energy gain about $60 \mathrm{MeV}$ in the DLW "Kharkov-65" of the $4.342 \mathrm{~m}$ length, it needs RF power source of $58 \mathrm{MW}$. In this case simulation parameters for the first variant were as follows: i) the diode gun voltage was $25 \mathrm{kV}$, the current was $1.5 \mathrm{~A}$, the pulse duration was $100 \mathrm{~ns}$ (for example, such high voltage pulse duration can be obtained with the HTS 30103-GSM push-pull palser [22]), beam pulse rise and fall times were $18 \mathrm{~ns}$; ii) the RF power feeding the injector was $2 \mathrm{MW}$, the RF pulse duration was $800 \mathrm{~ns}$, pulse rise and fall times were $36 \mathrm{~ns}$; iii) the RF power feeding the accelerating section was $58 \mathrm{MW}$, pulse duration was $800 \mathrm{~ns}$, pulse rise and fall times were $36 \mathrm{~ns}$.

Simulation procedures included adjustments of appropriated phase shift between the buncher and the accelerating section, an amplitude of buncher field as well as starting time of the beam current pulse and its amplitude to achieve the best compensation of beam loading. The main beam characteristics at the exit of accelerating section for the first variant are shown in Fig. 13.

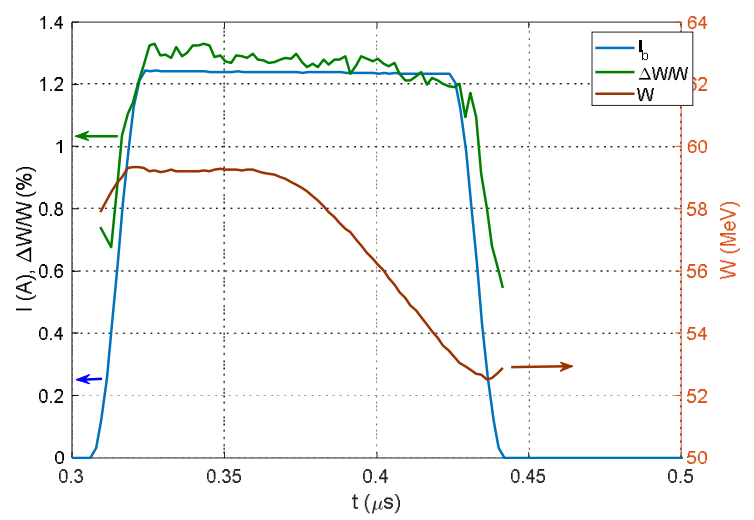

Fig. 13. Output beam characteristics of the first variant. Beam current (the blue curve, the left axis), energy spread (the green curve, the left axis), average beam energy (the brown curve, the right axis)

What we can learn from the curves is that beam loading is compensated only for about 50 ns of beam pulse duration at $1.23 \mathrm{~A}$ of output current. It is obviously also that energy and energy spread are different at rise and fall times of a beam current pulse from that for the rest of the beam pulse. Therefore, to get good beam loading compensation at beam current of $1.23 \mathrm{~A}$ it is necessary to use $50 \mathrm{~ns}$ beam pulse with as short rise and fall times as possible.

Such beam pulse time profile can be provided with the triode gun. Therefore, the second variant was simulated with following parameters: i) the triode gun voltage was $25 \mathrm{kV}$, current was $1.5 \mathrm{~A}$, flat top pulse duration was $40 \mathrm{~ns}$, beam pulse rise and fall times were $5 \mathrm{~ns}$; ii) the RF power feeding the injector was $2 \mathrm{MW}$, the pulse duration was $800 \mathrm{~ns}$, pulse rise and fall times were $36 \mathrm{~ns}$; iii) the RF power feeding the accelerating section was $58 \mathrm{MW}$, the pulse duration was $800 \mathrm{~ns}$, pulse rise and fall times were $36 \mathrm{~ns}$.

Time profiles of accelerating field at the entrance and the exit of the section as well as output beam pulse are presented in Fig. 14 for the beam pulse duration of $45 \mathrm{~ns}$.

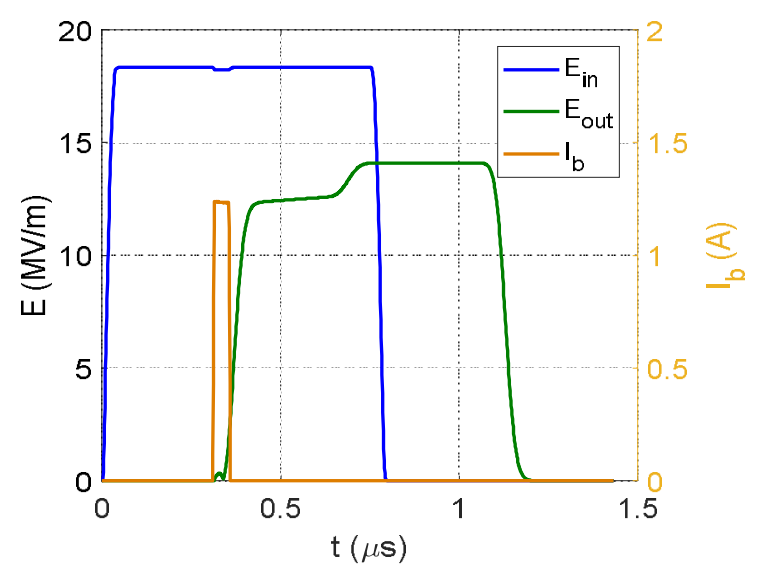

Fig. 14. Accelerating fields at the entrance (the blue curve, the left axis) and the exit (the green curve, the left axis) of the section and output current (the brown curve, the right axis)

One can see that beam is accelerated mainly in the yet unfilled section. Influence of the two opposite effects allows compensation of beam energy change. One of these effects is buildup of field excited by accelerated beam that leads to diminishing of energy gain with time. Result of interaction of these effects is shown in Figs. 15 and 16.

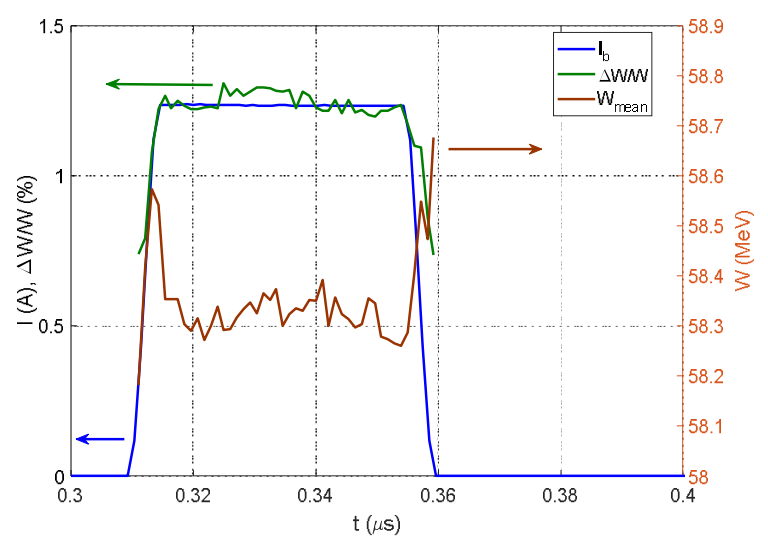

Fig. 15. Output beam characteristics of the second variant. Beam current (the blue curve, the left axis), energy spread (the green curve, the left axis), average beam energy (the brown curve, the right axis)

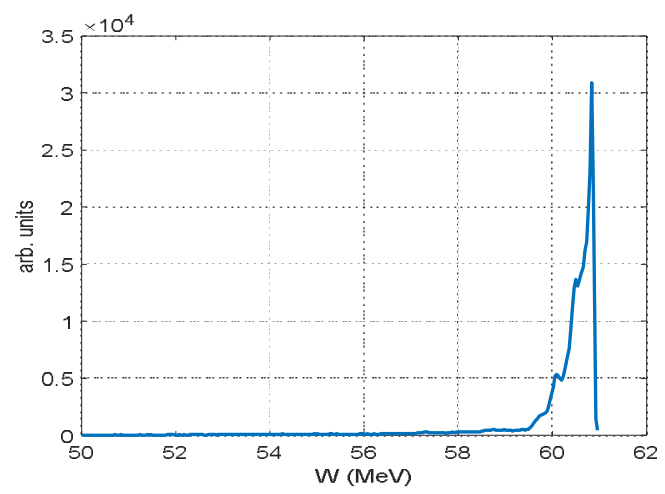

Fig. 16. Energy spread at the section exit for the second variant

It is clear from the Fig. 15 that change of average beam energy due to beam loading is well within intrabunch energy spread represented by the green curve.

Beam parameters at the exit of the accelerating section are summarized in Table 1. 
Table 1

Beam parameters for the second variant

\begin{tabular}{|l|l|}
\hline $\mathrm{I}_{\mathrm{b}}(\mathrm{A})$ & 1.23 \\
\hline Bunch charge $(\mathrm{nC})$ & 0.44 \\
\hline $\mathrm{W}_{\text {mean }}(\mathrm{MeV})$ & 58.3 \\
\hline $\mathrm{W}_{\text {pic }}(\mathrm{MeV})$ & 60.8 \\
\hline Energy spread (70\% of particles, \% ) & 1.2 \\
\hline Energy spread FWHM (\%) & 0.3 \\
\hline Phase spread (degree) & 17 \\
\hline Beam size (70\% of particles, cm) & 0.4 \\
\hline RMS Beam size (cm) & 0.3 \\
\hline Normalized transversal emittance $(\mathrm{mm} \cdot \mathrm{mrad})$ & 69 \\
\hline
\end{tabular}

As it follows from Table 1 there are 142 bunches with $0.44 \mathrm{nC}$ charge each, total $62 \mathrm{nC}$. In case of beam injection into the ring, only each forth bunch can be captured into the ring (bucket repetition rate in the ring is $700 \mathrm{MHz}$ that equals to the forth subharmonic of the linac frequency) so $\leq 16 \mathrm{nC}$ can be delivered to the ring orbit by one shot of the linac. Another three of four bunches will be lost in the ring. To diminish these losses, it is necessary to use gun current modulation with operating frequency of the ring. Because the linac is equipped with the main frequency buncher it is possible to cut out only two bunches of four unlike of subharmonic buncher that can generate just one bunch of four.

A half of accelerated bunches means a half of total charge accelerated within a current pulse length. To stay in conditions of high gradient acceleration for beam loading compensation it is necessary to double the gun current. In case of keeping the same gun current it is necessary to diminish RF power supply of the accelerating section, so we proceed to the case of low gradient acceleration.

\subsection{LOW GRADIENT ACCELERATION}

For decreased the fed RF power of $32 \mathrm{MW}$, the length of the "Kharkov-65" is not enough to achieve compensation of beam loading. To increase the section length, it is possible to use one more the $1.7 \mathrm{~m}$ long accelerating section that is available at NSC KIPT. The electrodynamic characteristics of this section are the same as that of the "Kharkov-65" with the same length. RF power from an output waveguide of the "Kharkov65 " have to be directed to that short accelerating section in an appropriated phase as input RF power. The total length of this composite accelerating section is $6.03 \mathrm{~m}$. In the simulation we just increased number of the section cells up to 225 .

Therefore, in order to eliminate a half of accelerated bunches we propose to use $45 \mathrm{~ns}$ grid pulser in combination with $700 \mathrm{MHz}$ RF voltage applied to the gun cathode-grid assembly that is phase locked to $2797.15 \mathrm{MHz}$ frequency. It should be noted that the amplitude of bias as well as amplitude and phase of $700 \mathrm{MHz}$ signal are adjusted in such a way to obtain two the same bunches at the injector exit within each $700 \mathrm{MHz}$ period (Fig. 17).

In this way the third variant adopted lover level of RF power feeding the injector and the acceleration section: i) the triode gun voltage was $25 \mathrm{kV}$, gun current was $1.35 \mathrm{~A}$; ii) the RF power feeding the injector was 1.5 MW, pulse duration was $800 \mathrm{ns,}$, pulse rise and fall times were $36 \mathrm{~ns}$; iii) the RF power feeding the accelerating section was $32 \mathrm{MW}$, pulse duration was $800 \mathrm{ns,}$ pulse rise and fall times were $36 \mathrm{~ns}$.

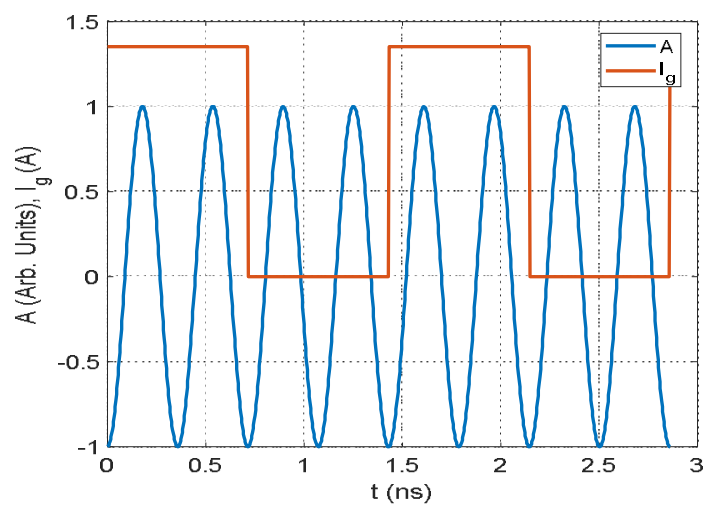

Fig. 17. Phasing of gun modulation signal relatively to field in the buncher

At simulation with the PARMELA code using technique [18] gun current has been set to zero every third and fourth periods of the linac operating frequency. Therefore, every circle, diamond or triangle in Fig. 18 represents beam parameter for two successive periods with none zero current. The energy spread for the total current pulse is shown in Fig. 19.

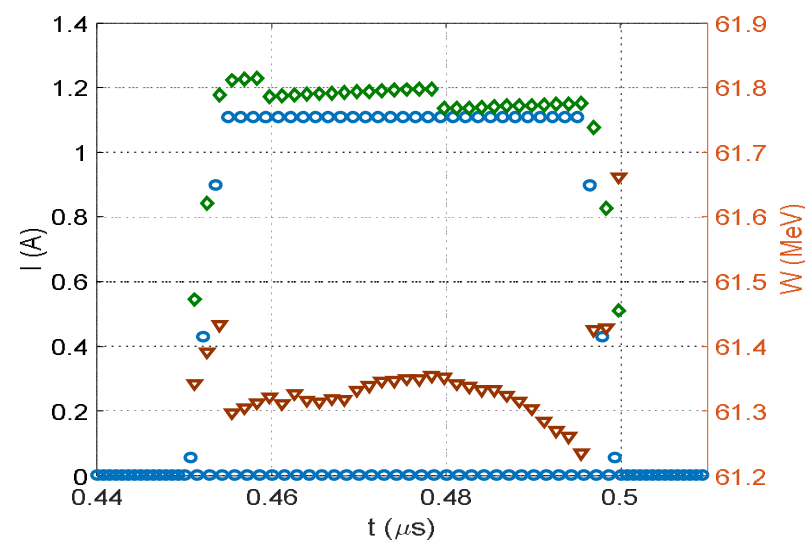

Fig. 18. Output beam characteristics of the third variant. Beam current (the blue circles, the left axis), energy spread (the green diamonds, the left axis), average beam energy (the brown triangles, the right axis)

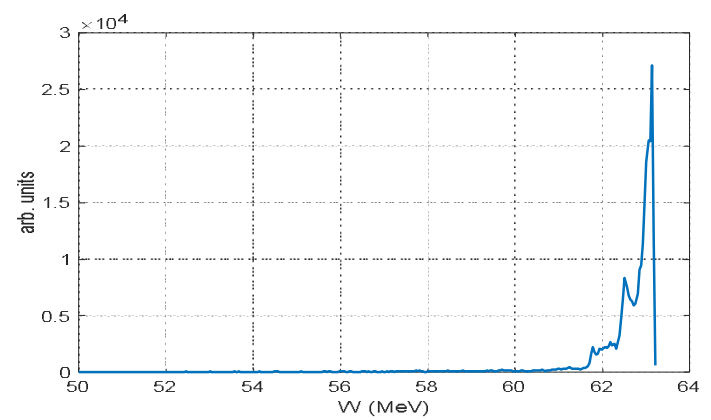

Fig. 19. Energy spread at the section exit for the third variant

One can see that change of average beam energy due to beam loading is well within intrabunch energy spread for this variant too. Beam parameters at the exit of the accelerating section for the third variant are summarized in Table 2. 
Table 2 6. W. Mondelaers et al. Transient Beam Loading Com-

Beam parameters for the third variant

\begin{tabular}{|l|l|}
\hline $\mathrm{I}_{\mathrm{b}}(\mathrm{A})$ & 1.1 \\
\hline Bunch charge $(\mathrm{nC})$ & 0.39 \\
\hline $\mathrm{W}_{\text {mean }}(\mathrm{MeV})$ & 61.3 \\
\hline $\mathrm{W}_{\text {pic }}(\mathrm{MeV})$ & 63.1 \\
\hline Energy spread $(70 \%$ of particles, \% $)$ & 1.18 \\
\hline Energy spread FWHM $(\%)$ & 0.26 \\
\hline Phase spread (degree) & 15.8 \\
\hline Beam size $\mathrm{D}_{\mathrm{x}, \mathrm{y}}(70 \%$ of particles, $\mathrm{cm})$ & 0.28 \\
\hline RMS Beam size $\mathrm{s}_{\mathrm{x}, \mathrm{y}}(\mathrm{cm})$ & 0.24 \\
\hline Normalized transversal emittance $\varepsilon_{\mathrm{x}, \mathrm{y}}(\mathrm{mm} \cdot \mathrm{mrad})$ & 46 \\
\hline
\end{tabular}

It can be seen from comparison Tables 1 and 2 that beam parameters for the third variant are even beater due to lower beam current. For the last case we have 71 bunches with $0.39 \mathrm{nC}$ charge each, total $28 \mathrm{nC}$. A half can be captured into the ring $(\leq 14 \mathrm{nC})$ by one shot of the linac.

\section{SUMMARY}

Acceleration of intense short-pulsed electron beams in transient mode with energy spread about a few percents is the actual problem for RF linacs, in an instance, for an electron injector of a storage ring. Unsteady selfconsistent beam dynamics in the one section RF linac fed from SLED was studied both analytically and numerically. For compensation of the transient beam loading, resulting in beam energy spread, a method of a beam delay with respect to RF pulse was consider .In order to increase efficiency of this method we choose a homogenous dick-loaded waveguide with $\pi / 2$ phase advance as an accelerating structure that characterized by the minimal frequency dispersion of group velocity. The preliminary results show that the full beam loading compensation is possible for electron beam with bunch charge about $0.4 \mathrm{nC}$ at its acceleration up to $60 \mathrm{MeV}$ during $50 \mathrm{~ns}$.

Results of performed analytical estimations and numerical simulations are in good agreement.

Proposed layout can be considered as the electron injector for the NESTOR storage ring. Although we chose such equipment of the simulated linac because it is available at NSC KIPT, but similar results can be obtained with proposed technique for the injector and the accelerating section redesigned for more convenient S-band frequency of $2856 \mathrm{MHz}$.

\section{REFERENCES}

1. V. Androsov, E. Bulyak, A. Dovbnya, et al. Status of Kharkov X-Ray Generator NESTOR Based on Compton Back Scattering // Proc. of EPAC08, Genoa, Italy, 2008, MOPC047, p. 175-177.

2. J. Leiss. Linear Accelerator / Edt. by P. Lapostolle and A. Septier, Amsterdam, Netherlands: NorthHolland, 1970.

3. J.W. Wang. Rf Properties of Periodic Accelerating Structures for Linear SLAC. 339, UC - 28, (A).

4. K.A. Thompson and R.D. Ruth. Simulation and Compensation of Multibunch Energy Variation in NLC // PAC, 1993, p. 3693; http://www.JACoW.org.

5. C. Adolphsen et al. SLAC-PUB-7518 (May 1997). pensation in Low-Energy Pulsed Linear Electron Accelerators // LINAC'00, Monterey, Aug. 2000, MOE08, p. 284 (2000); http://www.JACoW.org.

7. Z. Li, R. Miller, D. Farkas, T.O. Raubenheimer, et al. Beam loading compensation for the NLC low frequency linacs: Preprint SLAC-PUB-7429, 1997, 7p.

8. Z.D. Farkas, H.A. Hogg, G.A. Loew, P.B. Wilson. Recent progress on SLED, the SLAC energy doubler: Preprint SLAC-PUB-1561, March 1975.

9. A. Opanasenko. Transient beam loading compensation at $\mathrm{rf}$ acceleration of intense short-pulsed electron beams // Proc. of IPAC. Kyoto, Japan, 2010, p. 1363-1365, TUPEA017.

10. V. Androsov, O. Bezdetko, V. Boriskin, et al. The Start of X-Ray Generator NESTOR Comissioning // Problems of Atomic Science and Technology. 2013, № 6, p. 20-23.

11. M.I. Ayzatskiy, K.Yu. Kramarenko, I.V. Khodak, et al. Performance of Compact Electron Injector on Evanescent Oscillations // Proc. of the EPAC. Genoa, Italy, 2008, p. 790-792.

12. A.K. Valter, I.A. Grishaev, E.V. Eremenko, et al. $2 \mathrm{GeV}$ traveling wave electron accelerator // Proc. 5th International Conference on High-Energy Accelerators, HEACC 1965: Frascati, Italy, September 09-16, 1965, p. 233-238.

13. P.B. Wilson, Z.D. Farkas, and R.D. Ruth. SLED II: A new method of RF pulse com-pression // Proceedings of the Linear Accelera-tor Conference. 1990, Albuquerque, New Mexico, USA, p. 204-206.

14. S.G. Tantawi, C. Adolphsen, S. Holmes, et al. The next linear collider test accelerator's rf pulse compression and transmission systems // Proc. of PAC97, Vancouver, B.C., Canada, 12-16 May 1997, p. 3192-3194.

15. Ficbig and Ch. Schieblich. A SLED type pulse compres-sor with rectangular pulse shape // Proc. of 2 nd European Particle Accelerator Conference, Nice, France, 12-16 Jun 1990, p. 937-939.

16. G. Shu, F. Zhao, S. Pei. RF modulation studies on the $\mathrm{s}$ band pulse compressor // Proc. of IPAC2015, Richmond, VA, USA, WEPMN011, p. 2937-2939.

17. V.V. Mytrochenko and A.N. Opanasenko. Study of transient self-consistent beam dynamics in RF linacs using a particle tracing code // NIM A 558. 2006, p. 235-239.

18. L.M. Young. PARMELA, Los Alamos, Preprint LANL, LA-UR-96-1835, 1996, 108 p.

19. J.H. Billen and L.M. Young. Poisson Superfish Los Alamos: 1996, 43 p. (preprint / Los Alamos National Laboratory, LA-UR-96-1834).

20. G.A. Loew, R.H. Miller, R.A. Early, and K.L. Bane // IEEE Trans. Nucl. Sci. NS-26, 1979, p. 3701.

21. W.B. Herrmannsfeldt. Developments in the Electron Gun Simulation Program, EGUN, Stanford: 1994, 12 p. (preprint / Stanford Linear Accelerator Center, SLAC-PUB-6726).

22. Fast High Voltage Transistor Switch // https:/www.behlke.com/pdf/301-03-gsm.pdf.

Article received 13.02.2020 


\section{КОРОТКОИМПУЛЬСНЫЙ ЛИНЕЙНЫЙ УСКОРИТЕЛЬ ЭЛЕКТРОНОВ С ПОЛНОЙ КОМПЕНСАЦИЕЙ ТОКОВОЙ НАГРУЗКИ ПУЧКА}

\section{В.В. Митроченко, С.А. Пережогин, В.Ф. Жигло, А.Н. Опанасенко}

Ускорение интенсивных короткоимпульсных электронных пучков в переходном режиме с энергетическим разбросом в несколько процентов является актуальной проблемой для резонансных линейных ускорителей, например, для инжекторов электронов в накопительные кольца. Рассмотрена как аналитически, так и с помощью численного моделирования, нестационарная самосогласованная динамика пучка в односекционном резонансном линейном ускорителе, который питается от системы SLED. Для компенсации нагрузки пучком, которая является источником энергетического разброса, рассматривается метод задержки пучка относительно ВЧ-импульса. Для повышения эффективности этого метода в качестве ускоряющей структуры был избран однородный круглый волновод, нагруженный дисками, со сдвигом фазы на периоде 90 град, который характеризуется минимальной частотной дисперсией групповой скорости. Предварительные результаты показывают возможность полной компенсации нагрузки пучком для тока 1,2 А при ускорении частиц до 60 МэВ в течение 50 нс.

\section{КОРОТКОІМПУЛЬСНИЙ ЛІНІЙНИЙ ПРИСКОРЮВАЧ ЕЛЕКТРОНІВ З ПОВНОЮ КОМПЕНСАЦІЕЮ СТРУМОВОГО НАВАНТАЖЕННЯ ПУЧКА}

\section{В.В. Митроченко, С.О. Пережогін, В.Ф. Жигло, А.М. Опанасенко}

Прискорення інтенсивних короткоімпульсних електронних пучків у перехідному режимі з енергетичним розкидом у декілька відсотків $є$ актуальною проблемою для резонансних лінійних прискорювачів, наприклад, для інжекторів електронів у накопичувальні кільця. Розглянуто як аналітично, так і за допомогою числового моделювання нестаціонарну самоузгоджену динаміку пучка в односекційному резонансному лінійному прискорювачі, що живиться від системи SLED. Для компенсації навантаження пучком, що є джерелом енергетичного розкиду, розглядається метод затримки пучка відносно ВЧ-імпульсу. Для підвищення ефективності цього методу в якості прискорюючої структури було вибрано однорідний круглий хвилевід, навантажений дисками зі зсувом фази на періоді 90 град, що характеризується мінімальною частотною дисперсією групової швидкості. Попередні результати показують можливість повної компенсації навантаження пучком для струму 1,2 А при прискоренні часток до $60 \mathrm{MeB}$ за 50 нс. 